\title{
Influências das políticas e práticas de gestão de pessoas na institucionalização da cultura de segurança
}

\author{
Margareth Arpini Vieira ${ }^{a *}$, Annor da Silva Junior ${ }^{\mathrm{b}}$, Priscilla de Oliveira Martins da Silva ${ }^{\mathrm{c}}$ \\ ${ }^{a *}$ cad.vieira@hotmail.com, FUCAPE, Brasil \\ bannorsj@gmail.com, UFES, Brasil \\ cpriscillamartinssilva@gmail.com, UFES, Brasil
}

\begin{abstract}
Resumo
Objetivou-se descrever e analisar as influências das políticas e práticas de gestão de pessoas no processo de institucionalização da cultura de segurança numa indústria de grande porte. Teoricamente articularam-se quatro eixos centrais: (1) processo de institucionalização (BERGER; LUCKMANN, 2008); (2) segurança e cultura de segurança (HANSEN, 1993; GELLER, 2002); (3) políticas e práticas de gestão de pessoas (FLEURY; FISCHER, 1996); e (4) liderança e processo de mudança cultural (SCHEIN, 2004; SMIRCICH; MORGAN, 1997). Realizou-se um estudo de caso qualitativo (YIN, 2005; TRIVIÑOS, 2008), sendo os dados coletados via triangulação (JICK, 1979) e submetidos a análise temática de conteúdo (BARDIN, 2009; MINAYO, 2008). Evidências empíricas indicam o reconhecimento do papel da área de gestão de pessoas no processo de institucionalização da cultura de segurança, que encontra no fator humano o seu "dificultador”, pois, em grande parte das situações, é atribuído ao trabalhador a responsabilidade pela ocorrência do acidente.
\end{abstract}

Palavras-chave

Segurança do trabalho. Cultura de segurança. Processo de institucionalização. Políticas e práticas de gestão de pessoas.

\section{Introdução}

Pretendeu-se neste estudo descrever e analisar as influências das políticas e práticas de gestão de pessoas no processo de institucionalização da cultura de segurança. Nos últimos anos, o tema segurança do trabalho tem sido objeto de atenção contínua nos diversos segmentos industriais, tornando-se um desafio para a maioria das organizações, na medida em que as consequências decorrentes dos acidentes afetam os trabalhadores, as empresas, o governo e a sociedade como um todo (CARDELLA, 2008).

Segundo lita (1991), no passado havia certos mitos na área de segurança que colocavam a culpa do acidente no próprio acidentado, isentando, dessa forma, os responsáveis pela criação de situações perigosas de trabalho, o contexto do trabalho e a própria organização. Sob essa perspectiva, cabia à área de segurança desenvolver avaliações e ações voltadas para a predisposição do indivíduo em provocar o acidente no trabalho como forma de inibir a incidência de acidentes. Assumindo que o comportamento humano não é constante, que não segue padrões estabelecidos e é influenciado pelo contexto, esses mitos ficaram no passado, indicando que o problema da segurança do trabalho é muito mais complexo e envolve diversos fatores.

$\mathrm{Na}$ literatura especializada sobre segurança do trabalho é comum que se enfatizem os fatores mecânicos, físicos e biológicos que provocam os acidentes, porém pouco se aprofunda nos aspectos psicossociais, organizacionais e comportamentais (CHANLAT, 1995). Embora pouco explorado na literatura, segundo Cardella (2008), a quase totalidade das causas dos acidentes tem sido atribuída a fatores humanos.

Numa análise sistêmica das causas dos acidentes, Oliveira (2003) propõe a análise de um sistema de gestão de segurança sustentada por três pilares: (1) os aspectos culturais; (2) as ferramentas utilizadas 
para controle de risco; e (3) os objetivos definidos pela organização. Oliveira (2003) reforça ainda que os aspectos culturais são o fator mais significativo na medida em que podem facilitar ou dificultar os processos de mudanças na organização, sobretudo aqueles que podem contribuir para reverter os índices de acidentes no trabalho.

Sob essa óptica, Migueles, Lafraia e Souza (2006) fazem referência à cultura como um elemento que interfere na forma como a pessoa percebe a realidade, que, por sua vez, interfere nas ações práticas. Assim, o desenvolvimento e a presença de uma cultura voltada para a segurança do trabalho representam fatores fundamentais para direcionar os comportamentos individuais e coletivos para a realização do trabalho seguro e a prevenção de acidentes.

Do ponto de vista teórico, o desenvolvimento de uma cultura relaciona-se ao processo de institucionalização. $\mathrm{Na}$ institucionalização da cultura de segurança as organizações apresentam diferentes estágios. Os estágios evoluem desde a ausência de gestão em segurança até o nível em que a gestão é compartilhada por todos. Esse último estágio, denominado de cultura interdependente, é considerado o estágio da excelência na cultura de segurança, na medida em que a segurança passa a ser percebida como um valor e sinônimo de eficácia organizacional (HANSEN, 1993).

$\mathrm{Na}$ busca de uma estratégia efetiva para a institucionalização da cultura de interdependência, pressupõe-se que as organizações façam uma análise do estágio de sua cultura de segurança, bem como busquem o desenvolvimento e aplicação de práticas de gestão de pessoas no sentido de desenvolverem a autodisciplina, autonomia e participação dos trabalhadores (MIGUELES; LAFRAIA; SOUZA, 2006). Segundo Bley (2006), é necessário que as políticas e práticas de gestão de pessoas sejam revisadas, especialmente em relação ao processo de treinar e desenvolver as pessoas, tendo em vista o papel que elas têm no processo de prevenção de acidentes no trabalho.

Visto dessa forma, assume-se neste estudo que as políticas e práticas de gestão de pessoas estão associadas ao processo de institucionalização da cultura de segurança. Ao assumir essa associação se definiu o problema de pesquisa que norteou o estudo: De que forma as políticas e práticas de gestão de pessoas interferem na institucionalização da cultura de segurança em uma organização industrial de grande porte? Buscou-se resposta a essa questão por meio de um estudo de caso qualitativo em uma indústria brasileira de grande porte do ramo de mineração e beneficiamento de minério de ferro aqui identificada como U-SEG (nome fictício).
Embora se reconheça que a abordagem tradicional encontrada na literatura articule a segurança do trabalho de forma abrangente, envolvendo ações e medidas preventivas de acidentes no trabalho e doenças ocupacionais (ZOCCHIO, 2001), não há neste estudo o propósito de explorar as questões referentes à saúde ocupacional, restringindo-se apenas aos aspectos relativos aos acidentes de trabalho.

0 artigo está estruturado em quatro partes além da presente introdução, quais sejam: o referencial teórico que fundamenta a análise; os aspectos metodológicos de operacionalização da pesquisa; a apresentação, análise e discussão dos resultados; e as considerações finais.

\section{Referencial teórico}

\subsection{O processo de institucionalização}

Antes de discutir o processo de institucionalização da cultura de segurança, torna-se necessário compreender o que vem a ser a institucionalização como processo. Para isso, recorreu-se a Berger e Luckmann (2008), que em seu livro $A$ construção social de realidade o definem como sendo a produção de tipificações (padronizações) recíprocas de ações habituais decorrentes da interação entre indivíduos.

Segundo Berger e Luckmann (2008), a tipificação das ações habituais que compõem as instituições é sempre partilhada. Esse processo de formação de hábitos precede toda institucionalização, na medida em que as ações executadas repetidamente tornam-se moldadas a um padrão, que podem ser seguidas e reproduzidas, gerando economia de esforço na tomada de decisões, considerando que ficam restritas as opções de ação. Nesse processo, ocorre a interiorização dos valores, padrões, modelos, normas e símbolos sociais, que de fato efetivam o indivíduo como membro de uma sociedade (CASTRO, 2005).

A padronização do comportamento se forma numa configuração cultural através de dispositivos de controle, reforça Castro (2005), e quando esse processo de controle ocorre, pode-se dizer que houve o processo de institucionalização (BERGER; LUCKMANN, 2008). Enquanto norma de conduta, a instituição envolve um processo de internalização de regras e normas de ação com características duradouras que considera definição de papéis para assegurar a troca e 0 atendimento às normas (TATTO; JESUS, 2008). Ao caracterizar as diferentes etapas do processo de institucionalização, Berger e Luckman (2008) referem-se à primeira etapa como "exteriorização", que é a tipificação recíproca de ações habituais 
por atores. Essas instituições, já sedimentadas, são experimentadas como existindo independentemente dos indivíduos que as experimentam como possuindo realidade própria. Essa é a fase da "objetivação", na qual se argumenta o "é assim que as coisas são". A terceira etapa desse processo é a "internalização", momento em que se dá a apreensão do mundo como realidade social dotada de sentido.

Por fim, a última etapa em que ocorre a institucionalização total depende da sedimentação, a qual representa o momento em que as experiências ficam retidas e consolidadas na lembrança. Após ter realizado o processo de internalização é que, na realidade, o indivíduo se torna membro da sociedade, e o processo pelo qual isso se realiza é a socialização (BERGER; LUCKMANN, 2008).

\subsection{A segurança e a cultura de segurança}

De forma geral, a segurança do trabalho é considerada um conjunto de ações que tem a intenção de reduzir danos e perdas provocados por agentes agressivos (CARDELA, 2008). Essas ações incluem medidas técnicas, administrativas, educacionais, médicas e psicológicas aplicadas com o intuito de se obter um ambiente de trabalho mais seguro (RIBEIRO, 2006).

Via de regra, a incidência do acidente no trabalho (A Lei n. 8.213 de 24/7/1991 em seu artigo 19 define o acidente de trabalho como "aquele que ocorre pelo exercício do trabalho a serviço da organização ou pelo exercício do trabalho dos segurados especiais, provocando lesão corporal ou perturbação funcional que cause a morte, a perda ou a redução da capacidade para o trabalho, permanente ou temporária”. Quanto às razões para a ocorrência de acidentes de trabalho, Dessler (2003) cita três fatores: (a) condição insegura; (b) ato inseguro; e (c) acaso.) é determinado por várias causas, porém, o que é mais comum na literatura é enfatizar os fatores mecânicos, físicos e biológicos que provocam os acidentes em detrimento dos aspectos psicossociais, comportamentais e organizacionais, que ainda são pouco explorados (CHANLAT, 1995; BLEY, 2006). Embora esses três aspectos que sofrem interferência da cultura sejam negligenciados na literatura, na prática é muito comum responsabilizar (culpar) o trabalhador acidentado pela ocorrência do acidente no trabalho (CARDELLA, 2008).

No entanto, na visão de Oliveira (2003), a inclusão do comportamento do trabalhador no conjunto de fatores causais dos acidentes não significa encontrar o culpado pelo acidente, pelo contrário, é relevante considerar, com a finalidade de prevenção, quais foram os determinantes do comportamento que, direta ou indiretamente, motivaram o trabalhador a agir de determinada maneira que ocasionasse 0 acidente no trabalho.

Em seus estudos Dejours (1992) identificou que alguns trabalhadores apresentam resistência à prevenção ao demonstrarem aversão às normas de segurança. É como se a exposição ao risco caracterizasse traços de virilidade, bravura e orgulho. Além disso, as atitudes de desprezo pelo perigo

\section{[...] podem levar o trabalhador a acrescentar ao risco do trabalho o risco das performances pessoais e de verdadeiros concursos de habilidade e de bravura [...] (DEJOURS, 1992, p. 70).}

Em grande parte, esses aspectos comportamentais do trabalhador sofrem influência dos valores e da cultura da empresa (GANDRA; RAMALHO; CANÇADO, 2005). Para Migueles, Lafraia e Souza (2006), a cultura consiste em um conjunto de "mecanismos de controle" compreendido pelos planos, regras e instruções para governar o comportamento das pessoas, ou seja, a cultura controla líderes e liderados ao tornar compreensível o mundo em que vivem. Para os autores, o homem tem necessidade de tais mecanismos, pois dão forma a sua experiência, visto que "[...] a cultura é uma forma de impor um significado à experiência [...]" (MIGUELES; LAFRAIA; SOUZA, 2006, p. 30) que, ao ser analisada, deve-se considerar não somente valores e crenças compartilhados pelos indivíduos, mas o espaço social que está inserido. Ao assumir essa perspectiva de cultura, torna-se necessário explorar os aspectos ligados à cultura de segurança e como esta influencia o comportamento das pessoas e a incidência ou não de acidentes no trabalho.

0 conceito de cultura de segurança foi utilizado pela primeira vez durante o congresso da AIEA - Agência Internacional de Energia Atômica, realizado na França em 1986, após análise do acidente com a usina nuclear de Chernobil (GANDRA; RAMALHO; CANÇADO, 2005). De acordo com a Comissão de Saúde e Segurança do Reino Unido (apud REASON, 2000, p. 194) cultura de segurança de uma organização foi definida como:

Um produto de valores individuais e de grupo, atitudes, competências e padrões de comportamento que determinam o comprometimento para o estilo e proficiência de um programa de segurança da organização. Organizações com uma cultura positiva de segurança são caracterizadas por comunicações baseadas em mútua confiança, pela comunhão de percepções da importância da segurança e pela confiança na eficácia das medidas preventivas.

Sob a óptica da cultura de segurança, a abordagem é de que

[...] a cultura de segurança é uma forma de ver o mundo voltada para a prevenção e para redução de riscos [...] (MIGUELES; LAFRAIA; SOUZA, 2006, p. 31). 
Essa abordagem vai além de ter regras e procedimentos adequados, consiste em algo que orienta o comportamento sem a necessidade de padrões externos formalmente definidos ou em função de regras de punições. Isso fica evidente quando os valores são internalizados e as pessoas demonstram atitudes prevencionistas e zelosas para consigo mesmas e para com as demais.

Tendo como referência que a cultura organizacional num sentido mais amplo e a cultura de segurança num sentido mais estrito estão submetidas ao processo de institucionalização (BERGER; LUCKMANN, 2008) no contexto organizacional, diversos autores apresentaram perspectivas evolucionistas de estágios de desenvolvimento da cultura de segurança. Por exemplo, ao se basear em observações de como o fluxo de informações é tratado na organização, Westrum (1993) defendeu uma abordagem em que a cultura de segurança se desenvolve em três estágios: (1) a cultura patológica em que a informação não flui e é usada como vantagem pessoal dentro da organização; (2) a cultura calculativa em que a informação flui por meio de canais ou procedimentos eminentemente formais; e (3) a cultura construtiva em que a informação flui para a pessoa certa, no momento certo e da forma correta.

Hudson (2001), baseando-se em Westrum (1993), propôs um modelo de maturidade da cultura de segurança que amplia a abordagem original ao incluir dois novos estágios intermediários (o reativo e o proativo) aos três já existentes e substituir o termo "calculativo" por "burocrático". Com isso, a cultura de segurança evolui com o aumento de informação e de confiança na seguinte sequência: (1) cultura patológica, em que não há ações voltadas para a segurança do trabalho; (2) cultura reativa em que as ações voltadas para a segurança do trabalho somente são realizadas após a incidência de acidentes do trabalho; (3) cultura burocrática em que a organização possui sistemas para gerenciar riscos nos locais de trabalho em termos quantitativos; (4) cultura proativa em que as lideranças conduzem melhorias contínuas para a segurança do trabalho, antecipando-se aos problemas; e (5) cultura construtiva em que a organização possui um sistema integrado de saúde, segurança e meio ambiente, no qual se baseia e se orienta para realizar as ações produtivas e gerenciais relativas ao seu negócio.

Uma terceira perspectiva evolucionista da cultura de segurança foi desenvolvida por Hansen (1993). De acordo com o autor, o processo de segurança pode ser caracterizado por quatro níveis de eficácia, que ele denomina de "estágios da cultura de segurança", que as organizações podem alcançar. A descrição dessas etapas também é encontrada nos estudos de Geller (2002), as quais denomina de "visões culturais de segurança" e ressalta que o que determina a evolução para o estágio seguinte é o nível de amadurecimento da organização ou dos empregados. A seguir serão descritas as principais características de cada etapa de acordo com Hansen (1993) e Geller (2002):

1.Gestão por instinto: A segurança não apresenta nenhum processo de gestão. É caracterizada pela execução das práticas a partir da experiência ou do conhecimento técnico já adquirido. 0 traço cultural marcante é o paternalismo, prevalecendo um estilo de gestão autocrático e com foco nas tarefas;

2. Cultura dependente: Embora já tenha havido um avanço quanto à gestão de segurança, a gestão de segurança é reativa. Outra característica relevante dessa etapa é que os gerentes se eximem da responsabilidade pelos acidentes e culpam os empregados pelo ocorrido;

3. Cultura independente: Nesse estágio a segurança já é percebida de forma sistêmica, pois integra a segurança aos processos do negócio. As pessoas já começaram a incorporar a segurança como valor, no entanto ainda não agem com senso de coletividade; e

4. Cultura interdependente: Nesse último estágio já podem ser percebidos autodisciplina e a internalização das regras. A segurança se torna um valor da cultura organizacional. A característica essencial dessa etapa é a preocupação ativa com os outros, que é reforçada pelas consequências naturais de prestar ajuda.

Ressalta-se que o processo evolutivo é dinâmico e que nenhuma organização está totalmente em apenas um dos estágios (MIGUELES; LAFRAIA; SOUZA, 2006), ou seja, é possivel verificar a presença de posições híbridas entre um estágio e outro. É comum ainda que dentro de uma mesma organização identifiquem-se diferentes estágios, dependendo do setor, departamento ou área funcional, uma variação natural considerando o estágio de evolução que a organização se encontra.

Dentre as perspectivas evolutivas da cultura de segurança apresentadas, optou-se pelas abordagens de Hansen (1993) e Geller (2002), por serem mais coerentes com o recorte teórico e metodológico adotado na pesquisa, que tem como escopo apenas $o$ aspecto da segurança.

\subsection{Políticas e práticas de gestão de pessoas}

Ao abordar nessa pesquisa as políticas e práticas de gestão de pessoas, assume-se que as pessoas constituem o princípio essencial da organização, na medida em que inovam e recriam situações que podem levar a organização a posicionar-se de maneira diferenciada. 0 comportamento dos membros da 
organização interfere no seu funcionamento, na sua estrutura e nos princípios que the dão sustentação (DAVEL; VERGARA, 2001), inclusive nos aspectos relacionados à institucionalização da cultura de segurança.

A despeito das múltiplas abordagens e versões da gestão de pessoas, para responder ao problema de pesquisa proposto e alcançar os objetivos desse estudo, optou-se por considerar predominantemente a abordagem funcionalista, que considera o modelo de gestão de pessoas como um conjunto de políticas, práticas, padrões atitudinais e instrumentos, que uma organização utiliza para interferir e direcionar o comportamento humano para o ambiente de trabalho (FISHER, 2001).

Especificamente, as políticas e práticas de gestão de pessoas podem ser definidas como "[...] um conjunto de subsistemas que responde individualmente por cada uma das funções de recursos humanos [...]" (MARRAS, 2000, p. 62), e desempenham um papel relevante no processo de construção de identidade da organização, na medida em que os dogmas e os ritos implícitos nas políticas e nas práticas de pessoal intercedem na relação entre o indivíduo e a organização (FLEURY; FISCHER, 1996). Entre as principais políticas e práticas, Fleury e Fischer (1996) citam seis processos descritos a seguir, sem a intenção de esgotar toda a sua extensão e complexidade.

\subsubsection{Recrutamento e seleção}

0 objetivo principal desse processo é ajustar as características individuais com os objetivos do cargo, considerando as habilidades, conhecimentos, experiência e formação exigida (TACHIZAWA; FERREIRA; FORTUNA, 2001) de forma que a organização supra as suas necessidades de recursos humanos qualificados visando o atendimento de suas metas.

\subsubsection{Capacitação}

Mediante o processo de aprendizagem é possível o desenvolvimento de novas habilidades e aptidões, o que pode alterar a compreensão dos indivíduos sobre a realidade (FLEURY; OLIVEIRA JUNIOR, 2002). 0 processo de capacitação é uma necessidade da organização que eleva o desempenho profissional e a motivação dos trabalhadores (TACHIZAWA; FERREIRA; FORTUNA, 2001).

\subsubsection{Gestão da remuneração}

Esse processo consiste em estabelecer a política e os critérios de remuneração e benefícios (MARRAS, 2000). Na maioria das organizações os fatores que determinam a natureza do que os empregados recebem são os legais, sindicais, políticos e equitativos. Recomenda-se que a política de remuneração seja estruturada de modo que reforce os valores, crenças e o direcionamento estratégico da organização (HIPÓLITO, 2001).

\subsubsection{Avaliação de desempenho}

É considerado um conjunto de técnicas que tem como objetivo coletar e analisar as informações obtidas sobre a qualidade dos resultados do trabalho dos empregados (TACHIZAWA; FERREIRA; FORTUNA, 2001).

\subsubsection{Gestão de carreira}

Via de regra, o plano de carreira possui orientação alinhada ao objetivo principal da organização, permitindo com isso o melhor aproveitamento das pessoas, sua autorrealização pessoal e profissional (TACHIZAWA; FERREIRA, FORTUNA, 2001).

\subsubsection{Comunicação}

Articulado nas organizações em termos de três funções: (1) voltada para execução, monitoramento, controle e avaliação dos resultados; (2) voltada para a inovação ao abordar as necessidades da organização de comunicar as mudanças e procedimentos; e (3) relacionada à socialização, na medida em que aborda os meios de realização do trabalho (CASADO, 2002).

É com fundamento nesses seis processos que será analisado como as políticas e práticas de gestão de pessoas interferem na institucionalização da cultura de segurança em uma organização industrial. Complementarmente a essas políticas e práticas se entende ser necessário explorar também o papel das lideranças no processo de mudança cultural, inclusive de segurança, conforme será discutido a seguir.

\subsection{Liderança e o processo de mudança cultural na organização}

Uma organização bem-sucedida apresenta uma característica principal que a difere das demais: uma liderança dinâmica e eficaz (HERSEY; BLANCHARD, 1986). A liderança é considerada estratégica na medida em que tem a capacidade de influenciar outras pessoas a tomar, de forma voluntária e rotineira, as decisões que, de um lado, aumentam a viabilidade de longo prazo da organização e, de outro, mantêm a sua estabilidade financeira de curto prazo (ROWE, 2002).

As ações e declarações dos líderes contribuem para constituir o contexto organizacional, de forma 
que as pessoas na organização possam utilizar esse sentido criado como ponto de referência para sua própria ação e compreensão da situação vigente (SMIRCICH; MORGAN, 1997). Bergamini e Coda (1997) reforçam ainda que as ações e declarações do líder influenciam o imaginário dos liderados e os levam a modelar suas ações. Em outros termos, o líder, com suas práticas, causa impacto sobre os membros do grupo ao influenciar seus comportamentos a fim de atingir metas pessoais e organizacionais estabelecidas.

Schein (2004) argumenta que todos os líderes nas organizações precisam compreender a cultura organizacional, pois estas são criadas, manipuladas, transformadas e gerenciadas pelos líderes. Os líderes são, portanto, capazes de criar, mudar e manter e dar o sentido de determinadas ações, na medida em que delineiam e interpretam situações para guiar suas equipes, promovendo pontos de convergência e de divergência para a criação e modificação do próprio sentido.

Diante dessa concepção de liderança no processo de transformação cultural, Lacombe e Chu (2008) fazem referência à importância da política e práticas de gestão de pessoas, como meio para identificar e desenvolver comportamentos necessários à implementação de estratégias organizacionais.

\section{Aspectos metodológicos}

Metodologicamente, este estudo caracteriza-se como um estudo de caso qualitativo de natureza descritiva e analítica (TRIVIÑOS, 2008; YIN, 2005) em uma indústria do ramo de mineração aqui identificada como U-SEG. 0 critério de escolha dessa organização levou em consideração os seguintes aspectos: (a) organização com quadro funcional de aproximadamente mil empregos diretos; (b) operação classificada com grau de risco (Grau de risco é a gradação realizada pelo Ministério do Trabalho a cada tipo de atividade. Possui escala de 1 a 5. Essa gradação refere-se ao risco que a atividade proporciona aos seus empregados. Maiores informações consultar as Normas Regulamentadoras (NR).) 4; (c) possuir um modelo de gestão de recursos humanos e de gestão em segurança do trabalho em desenvolvimento; e (d) ser de fácil acessibilidade. Para orientar a análise dos dados elaborou-se o esquema analítico apresentado a seguir por meio da Figura 1.

A coleta dos dados ocorreu por meio da técnica triangulação (JICK, 1979) do tipo within method (Triangulação é definida como a utilização de dois ou mais métodos de pesquisa em um único estudo. Denzin (1989) identifica dois tipos de triangulação: (1) across method, que combina métodos de coleta de dados qualitativos e quantitativos; e (2) within method, que consiste na utilização de mais de um método de coleta de dados na mesma abordagem metodológica, seja ela qualitativa ou quantitativa.) (DENZIN, 1989; KIMCHI; POLIVKA; STEVENSON, 1991) ao articular (1) a realização de entrevistas semiestruturadas; (2) análise documental de fontes primárias e secundárias tais como o plano estratégico que definiu a missão, a visão e os valores da organização; o manual de gestão por competências; o manual de segurança; os resultados da pesquisa de indicadores de segurança; a metodologia de análise dos acidentes; e o relatório de Prêmio Nacional da Qualidade, entre outros; e (3) observações assistemáticas, que seguindo o roteiro previamente definido foram registradas em diário de campo.

0 roteiro de entrevista semiestruturado foi constituído em blocos, abrangendo o perfil sociodemográfico; as políticas e práticas de gestão de pessoas; a atuação das lideranças no processo de mudança cultural; e a segurança e o processo de institucionalização da cultura de segurança.

Foram entrevistados 20 sujeitos assim distribuídos: (1) duas lideranças da área de recursos humanos; (2) cinco lideranças da área de segurança do trabalho; (3) cinco lideranças da área de produção; e (4) oito empregados operacionais, sendo que alguns destes participavam da Comissão Interna de Prevenção de Acidentes (CIPA). Para a apresentação dos fragmentos das falas e dos discursos dos entrevistados utilizou-se como critério de codificação a posição ocupada na hierarquia, seguida de um número que distingue um entrevistado de outro, na forma seguinte: lideranças da área de recursos humanos (LRH + 1 ou 2); lideranças da

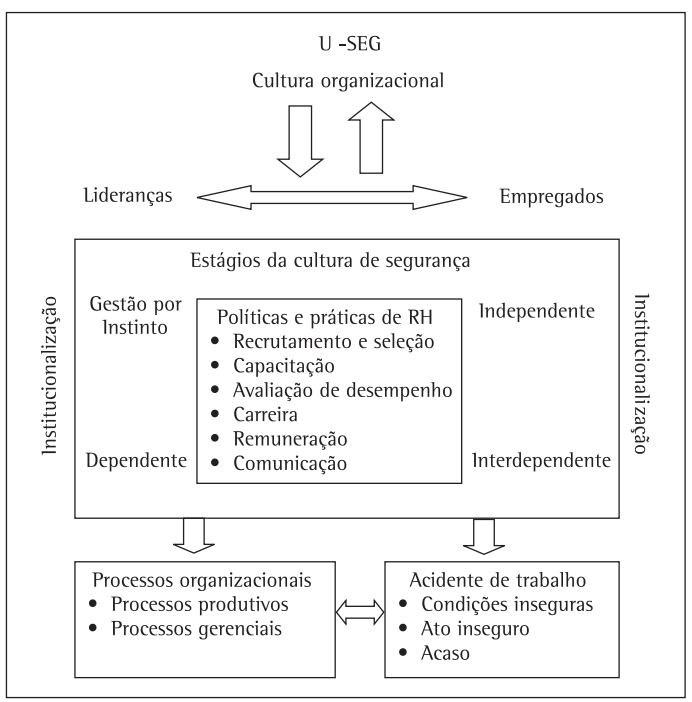

Figura 1. Esquema analítico que norteou a pesquisa. Fonte: elaborados pelos autores com fundamento em Hansen (1993), Geller (2002), Fleury e Fischer (1996), Marras (2000) e Dessler (2003). 
área de segurança do trabalho ( $\mathrm{LS}+1$ a 5 ), lideranças da área de produção (LPO + 1 a 5) e empregados operacionais (EPO + 1 a 8 ).

Os dados foram tratados por intermédio da análise de conteúdo do tipo temática (BARDIN, 2009; MINAYO, 2008) e agrupados em três categorias de uma grade fechada: (1) políticas e práticas de gestão de pessoas; (2) liderança e processo de mudança cultural; e (3) processo de institucionalização da cultura de segurança. Os dados serão apresentados e analisados a seguir.

\section{Apresentação e análise dos dados}

Estruturou-se a apresentação e análise dos dados em dois subtópicos: (1) apresentação da U-SEG; e (2) as três categorias que compõem a grade fechada.

\subsection{A U-SEG}

A U-SEG é uma indústria com atuação no setor de mineração e beneficiamento de minério de ferro, tendo toda a sua produção voltada para o mercado externo. Atualmente, ocupa posição de destaque no mercado transoceânico de pelotas de minério de ferro, matéria-prima para a produção do aço. Possui unidades industriais localizadas no Brasil, escritórios internacionais de vendas e usinas hidrelétricas, que abastecem parte de sua demanda energética. Sua força de trabalho no Brasil é constituída de aproximadamente 2 mil empregados diretos. Seu processo produtivo é integrado, abrangendo lavra, beneficiamento, condução, pelotização e exportação de minério de ferro.

As políticas, práticas e sistemas de gestão de recursos humanos e de segurança adotados são corporativos abrangendo todas as suas unidades industriais e escritórios. Com base no critério de acessibilidade, definiu-se como unidade-alvo dessa pesquisa uma unidade industrial situada na região Sudeste.

Segundo os registros e controles da área de segurança do trabalho, o histórico de acidentes na U-SEG é considerado baixo. A média anual de acidentes no período de realização da pesquisa foi de 0,56 . Considerando que a meta definida pela organização foi de 1,00, a média anual de acidentes ficou abaixo do limite definido como aceitável (ANÁLISE DOCUMENTAL).

\subsection{As categorias de análise}

Estruturou-se a apresentação e análise das categorias segundo a orientação processual estabelecida no problema de pesquisa. Embora tenha se optado pela apresentação dos dados subdivididos por categorias, isso não significa que não haja interdependência entre as categorias, pelo contrário, assume-se na pesquisa a relação sistêmica entre elas.

Objetivando analisar a institucionalização das políticas e práticas de gestão de pessoas em relação à cultura de segurança, optou-se pela polarização de pontos de vistas entre as lideranças (que reproduzem o discurso empresarial) e os empregados operacionais (que transformam ou não o discurso empresarial em hábito).

\subsubsection{Políticas e práticas de gestão de pessoas}

A análise das relações funcionais das políticas e práticas de gestão de pessoas leva ao entendimento de fatores que influenciam a relação entre o trabalhador e a segurança do trabalho (BLEY, 2006). Sob essa óptica evidenciou-se, durante as entrevistas, a análise documental e a observação assistemática, a percepção dos entrevistados acerca da interdependência entre as práticas de gestão de pessoas e as práticas voltadas para a segurança do trabalho. Observou-se entre as lideranças que a prática de gestão de pessoas mais destacada foi o processo de desenvolvimento e capacitação, sendo reconhecido como "um dos pontos fortes da gestão do RH” (LP04), seguido pelo diagnóstico e avaliação de acidentes, pelo processo de recrutamento e seleção de empregados e, por fim, pela avaliação de desempenho por competências (TACHIZAWA; FERREIRA; FORTUNA, 2001).

Outras práticas de gestão de pessoas foram citadas, porém sem reconhecimento por parte dos entrevistados da sua interdependência com a segurança do trabalho, tais como: a construção de ferramentas gerenciais; a construção do código de conduta; o programa de reconhecimento de idéias e, com menos frequência nos relatos, a administração da folha de pagamento, a resolução de conflitos e o estabelecimento de interface com comunidade.

Porém, constatou-se que na visão dos entrevistados alguns aspectos relacionados às práticas de gestão de pessoas e à segurança do trabalho precisam ser melhorados, conforme indicam os seguintes fragmentos:

1. 0 que eu acho é que a gente precisava pegar os programas fundamentais de RH [...] e esgotá-los e ter certeza que eles vão ser utilizados próximos da maestria (LS2).

2. [...] eu pedi inclusive para fazer um levantamento de qual o risco de evolução de um acidente. Talvez o RH consiga mostrar se há alguma evolução [...] é uma tentativa de ajudar a gente a enxergar alguma coisa que operacionalmente a gente não consegue perceber (LP1). 
3. De RH? Olha, conheço muito pouco [...] uma prática que o RH disponibiliza [...] são os treinamentos (EP03).

Dessas falas observa-se, de um lado, a proativativade na demanda por parte das lideranças (de segurança e de produção) quanto à melhoria contínua dos processos de segurança por meio das políticas e práticas de gestão de pessoas (FLEURY; FISCHER, 1996), uma vez que de forma sistemática indicam que o estágio atual pode ser considerado insuficiente para fundamentar a melhoria dos indicadores de segurança rumo à maestria (termo utilizado pelo entrevistado). De outro, a manifestação do empregado da produção que, do pouco que conhece de recursos humanos, reconhece no treinamento a preocupação central da organização com a sua segurança e da organização. Ao analisar esses dois pontos de vista, verifica-se o reconhecimento de lideranças e empregados do papel da área de gestão de pessoas ao intermediar a relação de produção com segurança.

No discurso dos entrevistados, destaca-se ainda a relevância do papel da prática de desenvolvimento e capacitação (FLEURY; OLIVEIRA JUNIOR, 2002) no processo de institucionalização (BERGER; LUCKMANN, 2008) da cultura de segurança (HANSEN, 1993; GELLER, 2002), uma vez que entende-se que é por meio desse processo que o indivíduo, além de desenvolver novas habilidades e aptidões, define padrões comportamentais que reforçam ações habituais em torno da segurança do trabalho.

\subsubsection{Liderança e processo de mudança cultural}

De forma geral, observa-se nos relatos que a atuação das lideranças é convergente com a concepção de Bergamini e Coda (1997) de que ações e as declarações do líder influenciam os liderados e os levam a modelar suas ações. A própria liderança atribui a si mesma uma responsabilidade expressiva pelos resultados de segurança, o que pode ser observado nos fragmentos a seguir:

4. A primeira questão é servir de fato como exemplo (LRH1).

5. A liderança tem que ir lá e mostrar como deve fazer, como deve se portar, o que deve ser utilizado, o que deve ser feito antes de iniciar (LPO1).

Essa responsabilidade também é atribuída às lideranças pelos empregados operacionais:

6. A atitude dos superiores é fundamental para que isso ocorra (referindo-se à segurança). Não é ficar só na palavra [...] você precisa visualizar essas práticas no dia a dia (EPO2).

Percebe-se nas falas supramencionadas a valorização da reprodução de comportamentos por meio dos exemplos, em que as ações e declarações dos líderes são utilizadas como ponto de referência para criação de sentido para as ações dos liderados (SMIRCICH; MORGAN, 1997). Ao se articular dessa forma, as práticas dos líderes impactam direta e indiretamente nas ações de segurança desenvolvidas pelos empregados.

Tendo em vista o papel que as lideranças exercem atualmente, alguns aspectos foram salientados por eles como necessários para envolver a equipe nas questões de segurança. Pode-se destacar a percepção da necessidade de conhecer bem suas equipes e estarem mais presentes em seu cotidiano. Os fragmentos indicam essa tendência:

7. [...] andando na área, conversando com as pessoas, identificando os problemas [...] porque às vezes uma pessoa que não está legal naquele dia, ela está com risco de acidente (LS3).

8. [...] tem que conhecer mais a rotina, os problemas, ouvir o povo da área, conversarem mais em DDS [diálogo diário de segurança]. Tem que ter maior compromisso gerencial [...] para os empregados serem capacitados (EP08).

Constatou que tanto as lideranças quanto os liderados reconhecem o importante papel das lideranças em conhecer o contexto de trabalho para, a partir daí, delinear e interpretar situações para conduzir suas equipes para o adequado desenvolvimento das atividades de trabalho com segurança. Com isso os líderes são capazes de criar, manipular, manter e gerenciar a cultura organizacional (SCHEIN, 2004).

\subsubsection{Processo de institucionalização da cultura de segurança}

Ao analisar os dados, verifica-se que a formação de hábitos precede toda a institucionalização. Na formação de hábitos constata-se que procedimentos e ações são executados repetidamente com vistas a moldar um padrão de comportamento a ser reproduzido gerando economia de esforços na tomada de decisão (BERGER; LUCKMANN, 2008). Os fragmentos a seguir ilustram esse processo:

9. A gente chega e faz o DDS, né. Então a gente não vai para a área sem fazer o diálogo de segurança. A análise de risco é um ritual (EPO3).

10. A gente não vai para a área sem a utilização dos EPls. lsso já é prática nossa mesmo (EP06).

11. Todos os dias a gente tem o DDS [...] o chefe reúne a equipe durante 20,30 minutos e discorre sobre um tema específico sobre segurança (LP04).

Importante ressaltar que o DDS e a análise preliminar de riscos (APR) foram mencionados em todas as entrevistas como um ritual diário, caracterizando-se 
como importantes instrumentos inseridos no processo de institucionalização da cultura de segurança.

Esse "ritual diário" torna-se um momento especial quando ocorrem acidentes na U-SEG. Nesses casos, a política institucional é de não punir o empregado pela incidência de acidentes. Além de relatar os fatos no DDS, os empregados envolvidos em acidentes e demais colegas participam da análise do acidente com o intuito de investigar e aprofundar as causas, sejam elas a condição insegura, o ato inseguro e/ou o acaso (DESSLER, 2003). A partir dessa análise coletiva, se define um plano de ação que pode envolver fatores diversos, tais como capacitação técnica e/ou comportamental para o empregado, aquisição de equipamentos, entre outros. Além disso, tanto o acidente quanto as causas envolvidas passam por um processo de divulgação para as áreas diretamente envolvidas e para todo o corpo gerencial. Com isso, as informações se multiplicam como forma de prevenção de novos acidentes.

Quanto à integração de novos empregados na organização, duas práticas foram relatadas com unanimidade. Eles passam por um treinamento de integração, cujo conteúdo depende da função que executarão e é pré-requisito para realizar suas atividades. A outra prática é o apadrinhamento. Por meio desse programa é designado um empregado experiente na função para acompanhar o recémadmitido nas suas atividades diárias durante um determinado período.

As falas seguintes ilustram a essência do discurso que as lideranças passam aos recém-chegados, bem como a internalização desses discursos por parte dos empregados após o período de integração na empresa.

12. Pensa em você. Se é arriscado você tem o direito de recusar, não faça (LP01).

13. Só faça aquilo que você tem absoluta certeza que está correto, se não, pergunte. Pare "n” vezes, não execute nada que você tenha dúvida (LP05).

14. [...] ele tem uma família que está esperando ele de volta... "Você veio para contribuir, para somar, desenvolver, mas a sua família está te esperando" (EP03).

15. Passar para ele a questão da prioridade da vida dele, sempre com atenção, qualquer atividade que fosse exercer (ЕР05).

Sobre o aspecto da recusa foram feitos relatos de empregados que, no contexto de suas atividades, ponderam com suas lideranças acerca do potencial de risco envolvido. Como respostas a essas ponderações, há lideranças que, a despeito dos riscos, insistem em manter o planejamento e execução da atividade e, outras, que optam por rever o planejamento e atrasar a entrega do serviço para executar a atividade com menor risco. Observa-se nesse caso a relevância do relacionamento liderança e liderado na forma de lidar preventivamente com os riscos das atividades que podem ocasionar acidentes no trabalho.

As falas e os relatos das lideranças e dos liderados reforçam que a padronização e a habitualização tanto das práticas quanto dos discursos têm papel relevante na institucionalização da cultura de segurança, permitindo com isso a sua evolução ao longo dos tempos no sentido da melhoria contínua.

Em termos da cultura de segurança constatou-se em todos os relatos o processo de evolução pelo qual a U-SEG vem passando. Iniciou numa etapa de trabalhar a organização e limpeza do ambiente até o momento atual em que "a segurança é declarada como um valor e passou a ser prioridade absoluta” (LRH1). Nas primeiras fases dessa evolução considerava-se que segurança antecedia a produção e atualmente o discurso é que "segurança tem que vir junto com produção” (LP02). Observa-se com isso que a U-SEG encontra-se em processo de transformação cultural, sob a óptica da segurança, conforme o relato seguinte:

16. [...] mas o que eu sinto é isso, é esse compromisso que a empresa tem com segurança, porque se eu avaliar quando eu entrei aqui e hoje, é totalmente diferente. (LPO3).

Entretanto, nesse processo de evolução e de direcionamento de esforços para conscientizar os trabalhadores da importância de cuidar de si e dos colegas, etapa fundamental para a excelência em segurança (HANSEN, 1993; GELLER, 2002), sobressaem dois aspectos: (1) as condições institucionais disponibilizadas para a prevenção de acidentes; e (2) o fator humano. Aparentemente, por um lado, há o reconhecimento por parte dos membros organizacionais que a U-SEG proporciona os meios e as condições essenciais para uma organização segura ao dedicar-se a desenvolver sistemicamente a cultura de segurança. Porém, de outro lado, o indivíduo (seja liderança ou empregado operacional) reconhece a si próprio como o responsável por ocasionar acidentes no trabalho.

17. A empresa se preocupa demais com a segurança da gente, e na verdade essa preocupação deve e tem que ser individual (EPO3).

18. Tudo que você precisar para sua segurança pessoal você tem à sua disposição [...] eu acho que o que falta mesmo é comprometimento das pessoas (EP07).

19. Uma organização segura é cada um fazendo a sua parte (LP01).

20. Eu acho que o que é feito na verdade no dia a dia já é o suficiente para cada um, agora, depende de cada pessoa adquirir aquilo para si (LPO1).

Analisando os fragmentos de 17 a 20, constatam-se dois aspectos fundamentais quanto à segurança do 
trabalho e à incidência de acidentes: (1) a concepção sistêmica proposta por Oliveira (2003) que contempla os aspectos culturais, as ferramentas para controle de risco e os objetivos definidos pela organização; e (2) o reconhecimento de que a responsabilidade sobre os acidentes no trabalho esteja relacionada aos fatores humanos, ou seja, a ação do indivíduo (CARDELLA, 2008).

No que tange ao aspecto do reconhecimento individual por ocasionar acidentes de trabalho, constatou-se nas entrevistas que o trabalhador lida com uma situação paradoxal ao escutar das lideranças um discurso de que somente faça uma tarefa se tiver segurança e de que há o direito de recusa (FRAGMENTOS 12 e 13) e, ao mesmo tempo, a percepção de que há uma cobrança dessas mesmas lideranças (representantes do discurso organizacional) por resultados produtivos que irão impactar (positiva ou negativamente) na rentabilidade e na lucratividade da empresa. Em outros termos, observa-se que a autonomia do trabalhador operacional de recusar a realização de uma determinada atividade por considerá-la insegura encontra na percepção de pressão por produtividade e no medo do desemprego um agravante para a incidência de acidentes no trabalho. As falas seguintes demonstram essa percepção.

21. Eu acho que muita gente faz porque precisa trabalhar, o cara tem medo de recusar [...] mas é raro você ver alguém usar o direito de recusa (EP07).

22. Acidentes sempre vão acontecer [...] mas se for recusar de fazer o trabalho é demitido (EP08).

Em parte, as falas indicam que o discurso de autonomia do trabalhador pela segurança na prática não se materializa pelo receio de perder o emprego e, consequentemente, a renda e a cidadania. Embora o discurso das lideranças seja explícito nesse sentido, os empregados operacionais ainda não demonstram confiança em praticá-lo habitualmente. Uma possível explicação para isso relaciona-se ao fato de que o trabalhador não participa efetivamente da discussão e decisão sobre as questões de segurança, conforme revelam as falas seguintes.

23. Não vejo participação não. 0 que eu vejo é a segurança do trabalho trazendo uma ferramenta que às vezes é uma novidade para a gente [...] dá um treinamento que a gente bota em prática (EPO3).

24. Depois que eu entrei, eu não me lembro de ter participado não [...] renovar ou inovar metodologias, não, não somos chamados para opinar (EP04).

Segundo Migueles, Lafraia e Souza (2006), um dos aspectos que contribuem para mudança de cultura em segurança é o trabalhador poder assumir a responsabilidade pelos processos e pelo aprimoramento de segurança na organização. 0 fato de esses trabalhadores assumirem que não têm participação ativa nas discussões e decisões sobre segurança indica que as lideranças e a organização ainda não assumiram na prática que a segurança seja de fato um valor conforme relatado anteriormente por uma das lideranças de recursos humanos (LRH1).

Outro aspecto relacionado à responsabilização do indivíduo pelos acidentes no trabalho é a percepção das próprias lideranças quanto a esse posicionamento do trabalhador operacional, conforme revela o fragmento seguinte.

25. Se eu vejo uma pessoa se submetendo a um trabalho insalubre, se eu vejo uma pessoa se expondo ao risco pela produtividade, isso de certa forma está arraigado na cultura do brasileiro, de aceitar isso [...] essa tolerância é cultural (LS2).

Aparentemente, ao atribuir a submissão do trabalhador ao risco de acidentes a questões da cultura brasileira indica a visão de que o trabalhador é de fato o elo mais fraco dessa corrente e que por não ter força submete-se ao risco pelo medo do desemprego. Em parte, isso significa que se estabelece nesse contexto um choque cultural, de um lado o esforço gerencial pela transformação de uma cultura de segurança e de outro a cultura brasileira de submissão do trabalhador apresentando-se como um fator de risco de acidentes de trabalho.

Com relação aos estágios da cultura de segurança (HANSEN, 1993; GELLER, 2002) poucos entrevistados demonstraram ter conhecimento do estágio em que a organização está. Apenas as lideranças e os empregados que atuam na Comissão Interna de Prevenção de Acidentes (CIPA). É relevante ressaltar que $90 \%$ dos empregados foram capacitados, por meio do Mapa de Aprendizagem, nos conceitos que abordam essas etapas.

Dos participantes, considerando lideranças e empregados da CIPA que demonstraram conhecimento sobre esses conceitos, há diferentes percepções sobre o estágio atual, uma vez que alguns acreditam que estão nos estágios mais básicos e outros nos mais avançados.

\section{Considerações finais}

A proposta desta pesquisa foi descrever e analisar como as políticas e práticas de recursos humanos interferem na institucionalização da cultura de segurança na organização industrial. Com esse objetivo, recorreu-se à abordagem de pesquisa qualitativa (TRIVIÑOS, 2008) para análise das falas das lideranças (representantes do discurso organizacional) e dos liderados acerca da segurança do trabalho, na U-SEG, uma indústria de grande porte no setor de mineração, tendo como fundamento três categorias de análise articuladas sistemicamente. 
Em termos das políticas e práticas de gestão de pessoas (FLEURY; FISCHER, 1996) observou-se o reconhecimento por parte das lideranças e liderados quanto ao papel da área de gestão de pessoas na construção e desenvolvimento de uma organização segura e da cultura de segurança. Nesse reconhecimento, constatou-se que para ambos, líderes e liderados, embora a U-SEG já tenha evoluído, ainda há muito que desenvolver. Nesse contexto, destaca-se que os programas de capacitação e desenvolvimento de pessoas têm contribuído significativamente para essa evolução.

Os dados revelam ainda o papel das lideranças, sejam elas da área de gestão de pessoas, de segurança ou de produção, em atuarem como agentes de mudança cultural. Para isso, reconheceu-se que aos líderes cabe conhecer o contexto de trabalho, seus liderados e recursos disponíveis para, então, guiar suas equipes em direção a uma organização segura (SCHEIN, 2004).

No que tange ao processo de institucionalização (BERGER; LUCKMANN, 2008) da cultura de segurança (HANSEN, 1993; GELLER, 2002), os dados indicam que a U-SEG vem evoluindo, ao assumir gradativamente a padronização e a habitualização de determinados processos e procedimentos que viabilizam a organização segura. Nesse processo de institucionalização há o reconhecimento dos envolvidos acerca das condições institucionais disponibilizadas pela organização para a prevenção de acidentes no trabalho, inclusive afirmando que a segurança é tida como um valor institucional. Além disso, identificam que o fator humano tem influência na ocorrência de acidentes ao assumirem eles próprios como responsáveis por tornar o ambiente de trabalho seguro e livre de acidentes.

$\mathrm{Na}$ institucionalização da cultura de segurança da U-SEG, observou-se que o fator humano é visto como o "calcanhar de Aquiles", pois, em grande parte das situações, é atribuída ao trabalhador a responsabilidade pela ocorrência do acidente, embora haja um discurso institucionalizado de que o operário tem o direito de recusar tarefas que considere inseguras. Como esse julgamento é valorativo e subjetivo, o trabalhador se vê numa situação paradoxal, em que a sua autonomia de decisão encontra, na percepção de cobrança por resultados de produção, o limite para esse julgamento. Em outros termos, a percepção da cobrança por produtividade e o receio de perder o emprego (por não cumprir com as metas de produção) fazem com que assuma para si o risco da insegurança que pode levar à incidência de acidentes no trabalho.

Diante do contexto analisado verifica-se que a U-SEG encontra-se em uma fase híbrida do estágio da cultura de segurança (HANSEN, 1993; GELLER, 2002), entre o nível da cultura dependente e da independente. Isso porque no atual momento a organização possui características típicas desses dois níveis. Embora a gestão de segurança possa ser considerada como proativa e as pessoas já percebam a segurança como um valor, ainda é comum que as lideranças eximam-se de suas responsabilidades ao culparem os empregados pela ocorrência de acidentes no trabalho.

Considera-se que os resultados da pesquisa permitem reflexões importantes sobre a problemática da segurança do trabalho. Uma delas está relacionada à utilização de modelos para a análise da cultura de segurança tanto para pesquisadores quanto para gerentes. Alinhados com a visão de Gonçalves Filho, Andrade e Marinho (2012), acredita-se que os modelos permitem diagnosticar a cultura de segurança de uma empresa de grande porte ou mesmo um conjunto de empresas simultaneamente, tendo em vista a limitação de recursos e de tempo. Como limitações inerentes ao estudo realizado, destaca-se, por exemplo, o enfoque dado exclusivamente à segurança do trabalho, deixando-se de se discutir aspectos ligados à saúde do trabalhador. Sugere-se, nesse sentido, que trabalhos posteriores busquem ampliar os estudos envolvendo os aspectos da saúde dos trabalhadores.

\section{Referências}

BARDIN, L. Análise de conteúdo. Lisboa: Edições 70, 2009.

BERGAMINI, C. W.; CODA, R. Psicodinâmica da vida organizacional. 2. ed. São Paulo: Atlas, 1997.

BERGER, P.; LUCKMANN, T. A construção social da realidade. 28. ed. Petrópolis: Vozes, 2008.

BLEY, J. Comportamento seguro. Curitiba: Sol, 2006.

CARDELLA, B. Segurança no trabalho e prevenção de acidentes. 6. ed. São Paulo: Atlas, 2008.

CASADO, T. 0 papel da comunicação interpessoal. In: FLEURY, M. T. L. (Org.). As pessoas na organização. 7. ed. São Paulo: Editora Gente, 2002. p. 271-282.

CASTRO, C. A. P. Sociologia aplicada à administração. 2. ed. São Paulo: Atlas, 2005.

CHANLAT, J. Modos de gestão, saúde e segurança no trabalho. In: DAVEL, E. P. B.; VASCONCELOS, J. G. (Orgs.). Recursos humanos e subjetividade. Petrópolis: Vozes, 1995. p. 118-128.

DAVEL, E. P. B.; VERGARA, S. C. Gestão com pessoas, subjetividade e objetividade nas organizações. In: DAVEL, E.; VERGARA, S. C. (Orgs.). Gestão com pessoas e subjetividade. São Paulo: Atlas, 2001. p. 31-56.

DEJOURS, C. A loucura do trabalho. 5 ed. ampl. São Paulo: Cortez Oboré, 1992.

DENZIN, N. The research act: a theoretical introduction to sociological methods. 3rd ed. New York: Prentice Hall, 1989.

DESSLER, G. Administração de recursos humanos. 2. ed. São Paulo: Prentice Hall, 2003

FLEURY, M. T. L.; OLIVEIRA JUNIOR, M. M. Aprendizagem e gestão do conhecimento. ln: FLEURY, M. T. L. (Org.). As pessoas na organização. 7. ed. São Paulo: Editora Gente, 2002. p. 133-146. 
FLEURY, M. T. L.; FISCHER, R. Cultura e poder nas organizações. 2. ed. São Paulo: Atlas, 1996.

FISHER, A. L. 0 conceito de modelo de gestão de pessoas. In: DUTRA, J. S. et al. (Org.). Gestão por competências. São Paulo: Editora Gente, 2001. p. 9-23.

GANDRA, J.; RAMALHO, W.; CANÇADO, R. Geração e validação de um modelo causal de acidentes. In: ENCONTRO DA ASSOCIAÇÃO NACIONAL DE PÓS GRADUAÇÃO EM ADMINISTRAÇÃO, 29., 2005, Brasília. Anais... Rio de Janeiro: ANPAD, 2005.

GELLER, E. S. Psycology of safety handbook. Boca Raton: Lewis Publishers, 2002.

GONÇALVES FILHO, A. P.; ANDRADE, J. C. S.; MARINHO M. M. O. Modelo para a gestão da cultura de segurança do trabalho em organizações industriais. Produção, v. 23, n. 1, p. 178-188, 2012. http://dx.doi.org/10.1590/ S0103-65132012005000044

HANSEN, L. L. Safety management. American Society of Safety Engineers, p. 16-21, mar. 1993.

HERSEY, P.; BLANCHARD, K. Psicologia para administradores. São Paulo: EPU, 1986.

HIPÓLITO, J. Tendências no campo da remuneração para o novo milênio. In: DUTRA, J. S. et al. (Org.). Gestão por competências. São Paulo: Editora Gente, 2001. p. 71-94.

HUDSON, P. Safety management and safety cultur: the long and winding road. Canberra: CASA, Sep. 2001.

IITA, 1. Novas abordagens em segurança do trabalho. Produção, v. 1, n. 2, p. 63-73, mar. 1991. http://dx.doi. org/10.1590/S0103-65131991000200001

JICK, T. D. Mixing quantitative and qualitative methods. Administrative Science Quarterly, n. 24, p. 602-611, 1979. http://dx.doi.org/10.2307/2392366

KIMCHI, J.; POLIVKA, B.; STEVENSON, J. S. Triangulation: operational definitions. Nursing Research, v. 40, n. 6, p. 364-366, 1991. http://dx.doi.org/10.1097/00006199199111000-00009
LACOMBE, M.; CHU, R. Políticas e práticas de gestão de pessoas. Revista de Administração de Empresas, p. 25-35. jan./mar. 2008.

MARRAS, J. P. Administração de recursos humanos. 11. ed. São Paulo: Futura, 2000.

MIGUELES, C.; LAFRAIA, J.; SOUZA, G. Criando o hábito da excelência. Rio de Janeiro: Ed Qualitymark, 2006.

MINAYO, M. O desafio do conhecimento. 11. ed. São Paulo: Hucitec, 2008.

OLIVEIRA, J. C. Segurança e saúde no trabalho. São Paulo em Perspectiva, v. 17, p. 2-12, 2003. http://dx.doi. org/10.1590/S0102-88392003000200002

REASON, J. Managing the risks of organizational accidents. Aldershot: Ashgate, 2000.

RIBEIR0, A. Gestão de pessoas. São Paulo: Saraiva, 2006.

ROWE, W. G. Liderança estratégica e criação de valor. Revista de Administração de Empresas, v. 42, n. 1, p. 7-19, 2002.

SCHEIN, E. Organizational culture and leadership. 3rd ed. San Francisco: Jessey Bess, 2004.

SMIRCICH, G.; MORGAN, G. Liderança. In: SMIRCICH, G.; MORGAN, G. Psicodinâmica da vida organizacional. 2. ed. São Paulo: Atlas, 1997. p. 205-228.

TATTO, L.; JESUS, M. A institucionalização da estratégia. In: ENCONTRO DE ESTUDOS ORGANIZACIONAIS ANPAD, 5., 2008, Belo Horizonte. Anais... Rio de Janeiro: ANPAD, 2008.

TACHIZAWA, T.; FERREIRA, V.; FORTUNA, A. Gestão com pessoas. Rio de Janeiro: Editora FGV, 2001.

TRIVIÑOS, A. N. B. Introdução à pesquisa em ciências sociais. 16. reimp. São Paulo: Atlas, 2008.

WESTRUM, R. Cultures with requisite imagination. In: WISE, J. A.; HOPKIN, V. D.; STAGER, P. (Eds.). Verification and validation of complex systems: human factors issues. New York: Springer-Verlag, 1993. p. 413-427.

YIN, R. K. Estudo de caso. 3. ed. Porto Alegre: Bookman, 2005.

ZOCCHIO, A. Segurança e saúde no trabalho. São Paulo: LTr, 2001.

\section{Influences of the human management policies and practices at a safety culture institutionalization process}

Abstract

The article aims to describe and analyze the influence of human management policies and practices at a safety culture institutionalization process in a high size industry. Theoretically four central axles were articulated: (1) institutionalization process (BERGER; LUCKMANN, 2008); (2) safety and safety culture (HANSEN, 1993; GELLER, 2002); (3) human management policies and practices (FLEURY; FISCHER, 1996); and, (4) leadership and the cultural change process (SCHEIN, 2004; SMIRCICH; MORGAN, 1997). It was realized a qualitative case study (YIN, 2005; TRIVIÑOS, 2008). Data were collected via triangulation (JICK, 1979) and submitted to thematic content analyses (BARDIN, 2009; MINAYO, 2008). Empirical evidences signalizes the recognition of the human management role at safety culture institutionalization process, that consider the human factor the "Achilles' heel", therefore, in most of situations it is imputed to the worker the responsibility to the accident event at work.

Keywords

Safety work. Safety culture. Institutionalization process. Human management policies and practices. 